\title{
Epidemiological characteristics and initial spatiotemporal visualisation of COVID-19 in a major city in the Middle East
}

Shahab MohammadEbrahimi ${ }^{1,2}$ (D), Alireza Mohammadi ${ }^{3^{*}}$ (D), Robert Bergquist ${ }^{4,5}$ (D), Fatemeh Dolatkhah ${ }^{2,6}$ (D), Mahsa Olia ${ }^{7}$ (D), Ayoub Tavakolian ${ }^{8}$ (D), Elahe Pishgar ${ }^{9}$ (D) and Behzad Kiani ${ }^{10^{*}}$ (D)

\begin{abstract}
Background: The Severe Acute Respiratory Syndrome Coronavirus-2 (SARS-CoV-2) emerged initially in China in December 2019 causing the COVID-19 disease, which quickly spread worldwide. Iran was one of the first countries outside China to be affected in a major way and is now under the spell of a fourth wave. This study aims to investigate the epidemiological characteristics of COVID-19 cases in north-eastern Iran through mapping the spatiotemporal trend of the disease.

Methods: The study comprises data of 4000 patients diagnosed by laboratory assays or clinical investigation from the beginning of the disease on Feb 14, 2020, until May 11, 2020. Epidemiological features and spatiotemporal trends of the disease in the study area were explored by classical statistical approaches and Geographic Information Systems.

Results: Most common symptoms were dyspnoea (69.4\%), cough (59.4\%), fever (54.4\%) and weakness (19.5\%). Approximately $82 \%$ of those who did not survive suffered from dyspnoea. The highest Case Fatality Rate (CFR) was related to those with cardiovascular disease (27.9\%) and/or diabetes (18.1\%). Old age ( $\geq 60$ years) was associated with an almost five-fold increased CFR. Odds Ratio (OR) showed malignancy (3.8), nervous diseases (2.2), and respiratory diseases (2.2) to be significantly associated with increased CFR with developments, such as hospitalization at the ICU (2.9) and LOS (1.1) also having high correlations. Furthermore, spatial analyses revealed a geographical pattern in terms of both incidence and mortality rates, with COVID-19 first being observed in suburban areas from where the disease swiftly spread into downtown reaching a peak between 25 February to 06 March (4 incidences per $\mathrm{km}^{2}$ ). Mortality peaked 3 weeks later after which the infection gradually decreased. Out of patients investigated by the spatiotemporal approach ( $n=727), 205$ (28.2\%) did not survive and 66.8\% of them were men.

Conclusions: Older adults and people with severe co-morbidities were at higher risk for developing serious complications due to COVID-19. Applying spatiotemporal methods to identify the transmission trends and high-risk areas can rapidly be documented, thereby assisting policymakers in designing and implementing tailored interventions to control and prevent not only COVID-19 but also other rapidly spreading epidemics/pandemics.
\end{abstract}

Keywords: Coronavirus, COVID-19, Disease mapping, Epidemiology, Geographical information systems, SARS-CoV-2, Spatiotemporal mapping

\footnotetext{
* Correspondence: A.Mohammadi@uma.ac.ir; Kiani.Behzad@gmail.com

${ }^{3}$ Department of Geography and Urban Planning, Faculty of Social Sciences, University of Mohaghegh Ardabili, Ardabil, Iran

${ }^{10}$ Department of Medical Informatics, School of Medicine, Mashhad University of Medical Sciences, Mashhad, Iran

Full list of author information is available at the end of the article
}

(c) The Author(s). 2021 Open Access This article is licensed under a Creative Commons Attribution 4.0 International License, which permits use, sharing, adaptation, distribution and reproduction in any medium or format, as long as you give appropriate credit to the original author(s) and the source, provide a link to the Creative Commons licence, and indicate if changes were made. The images or other third party material in this article are included in the article's Creative Commons licence, unless indicated otherwise in a credit line to the material. If material is not included in the article's Creative Commons licence and your intended use is not permitted by statutory regulation or exceeds the permitted use, you will need to obtain permission directly from the copyright holder. To view a copy of this licence, visit http://creativecommons.org/licenses/by/4.0/ The Creative Commons Public Domain Dedication waiver (http://creativecommons.org/publicdomain/zero/1.0/) applies to the data made available in this article, unless otherwise stated in a credit line to the data. 


\section{Introduction}

In December 2019, a novel coronavirus, the Severe Acute Respiratory Syndrome Coronavirus-2 (SARSCoV-2), was diagnosed in China. SARS-CoV-2 is the case of Coronavirus disease-2019 (COVID-19) that quickly spread to all countries around the world turning into a massive worldwide health concern $[1,2]$. This disease commonly causes severe respiratory deficiency resulting in increased admissions into Intensive Care Units (ICUs) with high mortality rates [3, 4].

Since the outbreak of COVID-19, research has been conducted with unparalleled speed to investigate the clinical and epidemiological features of the disease. Suleyman et al. [5] conducted a study in metropolitan Detroit in the U.S. that included 463 patients with COVID-19 showing that $94 \%$ of the patients had at least one comorbidity and their most common symptoms were cough, fever and dyspnoea, respectively. Age above 60 years, male sex, pronounced obesity and chronic renal disease were soon seen as strongly associated with ICU admission and an above-average Case Fatality Rate (CFR) [5]. In Wuhan, a retrospective study performed by Zhou et al. [6] involving 191 hospitalized patients, who had been discharged or died by 31 Jan 2020, showed that $50 \%$ of them had co-morbidities; the death rate was about 28\% $(n=54)$. Being old and having a higher sequential organ failure assessment score (SOFA) was significantly associated with increased CFR [6]. Another retrospective study in Wuhan, conducted on the 102 COVID-19 cases hospitalized between 31 Jan and 5 Mar 2020 , reported a mortality level of $15 \%$, with most fatalities being old [7]. Docherty et al. conducted a cohort study in the UK involving 20,133 hospital in-patients between 6 Feb and 19 Apr 2020, which showed that 60\% of those admitted were men and $77 \%$ had at least one co-morbidity, while $26 \%$ of the patients $(n=5165)$ eventually died [8].

Iranian studies report similar results, e.g., a retrospective study in Tehran [9] presented the infection rate as twice as common in men as in women, a CFR of $8 \%$, and a co-morbidity rate of $15.9 \%$ in those above 60 years. In another study conducted in Shiraz [10], 63\% of the patients were male, with fatigue, cough and fever as the most common symptoms. Here, $8 \%$ overall mortality and a significant association between ICU admission and death rate, were reported [10]. Although previous studies have shown that most COVID-19 cases have a promising prognosis [11], patients with underlying chronic co-morbidities would experience more serious health consequences, including a substantial CFR [12].

This new member of the coronavirus family is highly contagious. More than one and half a year after it first emerged, as of June 10, 2021, the number of confirmed cases has reached 175 million with close to 4 million deaths globally. Of these, close to 3 million cases and more than 81,000 deaths are Iran's share and it had the highest number of daily death caused by COVID-19 in November 2020 (>450) [13]. In order to generate the best response strategies, analysing and representing the spatial and temporal spread of the virus is crucial for epidemiologists and health policymakers [14]. Health organizations, especially World Health Organization (WHO), have increasingly applied spatial analysis to represent and control disease outbreaks. Geographic Information Systems (GISs) have shown successful results concerning contagious diseases, and applications are been shown highly useful in mapping geographical distribution of disease prevalence as well as visualising transmission trends and modelling spatial environmental aspects of disease occurrence [15-18]. Accordingly, the GIS toolbox is highly useful for decision-making, as well as understanding the spatiotemporal dynamics and control of COVID-19 [19, 20].

Most spatial analyses of the COVID-19 outbreak have been conducted in China. For example, Tang et al. [21] reviewed the daily data flow of new cases and identified hotspots in the areas where the virus originated in the study period. Furthermore, Fan et al. [22] showed that the spatial distribution pattern of confirmed COVID-19 cases followed a particular, geographical pattern. They found hotspots to be mainly restricted to the outbreak areas, especially in densely populated areas. In another study conducted in Hubei Province of China, researchers found significant spatial autocorrelation and clustering at the local level in the study area [23]. In India, spatiotemporal analysis of confirmed COVID-19 cases at the provincial level showed significant differences in disease incidence across the Indian provinces. As well, the potential capacity of a heavy COVID-19 outbreak in India in the future, was predicted by this study [24]. In contrast, a comprehensive GIS-based study in Catalonia, Spain showed a random distribution without a clear spatial pattern and any local autocorrelation based on Global Moran's $I$ [25].

In Iran, the work of Mazar et al. [26], in one of the first studies on the spatiotemporal distribution of COVID-19 outbreaks, examined the effects of travel on the spatial distribution of the infection. Their research focused on identifying areas with high prevalence rates, especially in the provinces where the virus originated. From the GIS-based maps, it was clear that the disease spread from the north-central provinces Tehran and Qom, known as the administrative and religious centres of the country, respectively, which both are important foci for travellers [26].

In the context of spatial analysis of the COVID-19 outbreak, most previous studies have been conducted at the macro-level (world, country or province), generally 
without addressing the epidemiological features of the pandemic. Here, we aimed to perform a spatiotemporal analysis of new infections in a big city. To the best of our knowledge, no such study has been done in Mashhad, the second-most populous city in Iran. Besides, this study was conducted while the study area was in a vigilant status with a high epidemic alert. Our approach can be used as a basis for future spatial modelling of the disease and provide valuable knowledge for preventive measures in the study area or other similar metropolitan areas.

\section{Methods}

\section{Study area and population}

Iran is a country in the Middle East with a population of more than 84 million people [27] located north-east of the Persian Gulf. The study area was the city of Mashhad, the capital of Khorasan-Razavi Province in north-eastern Iran. It is the most famous place of religious pilgrimage and tourist attraction in Iran attracting more than 20 million tourists and pilgrims annually $[28,29]$. Mashhad is situated between latitudes $36^{\circ} 10^{\prime}$ and $36^{\circ} 25^{\prime} \mathrm{N}$ and longitudes $59^{\circ} 25^{\prime}$ and $59^{\circ} 46^{\prime} \mathrm{E}$ covering an area of $307 \mathrm{~km}^{2}$ (Fig. 1). According to the 2016 national census, the city population was 3,372,660 [30]. Mashhad consists of about 17 municipality regions, 175 districts and 1301 census tracts. In our study, we used census tracts as the finest scale of analysis to make the results more accurate and more detailed.

\section{Study design and data collection}

This retrospective study was conducted at two levels. At the first level, all collected data were subjected to a statistical analysis rendering the general epidemiological characteristics of the pandemic, while at the second, we focused on a space-time analysis to identify the geographical trends of dissemination and clustering patterns of the disease.

The basis of the study was the collected COVID-19 data from the Mashhad University of Medical Sciences (MUMS). The study covered 3 months with the start coinciding with the beginning of the COVID-19 outbreak in Mashhad (14 Feb 2020) and continued until 11 May 2020. The data included 4000 people referred to the health-care centres and hospitals due to COVID-19 infection with cases either confirmed clinically or by

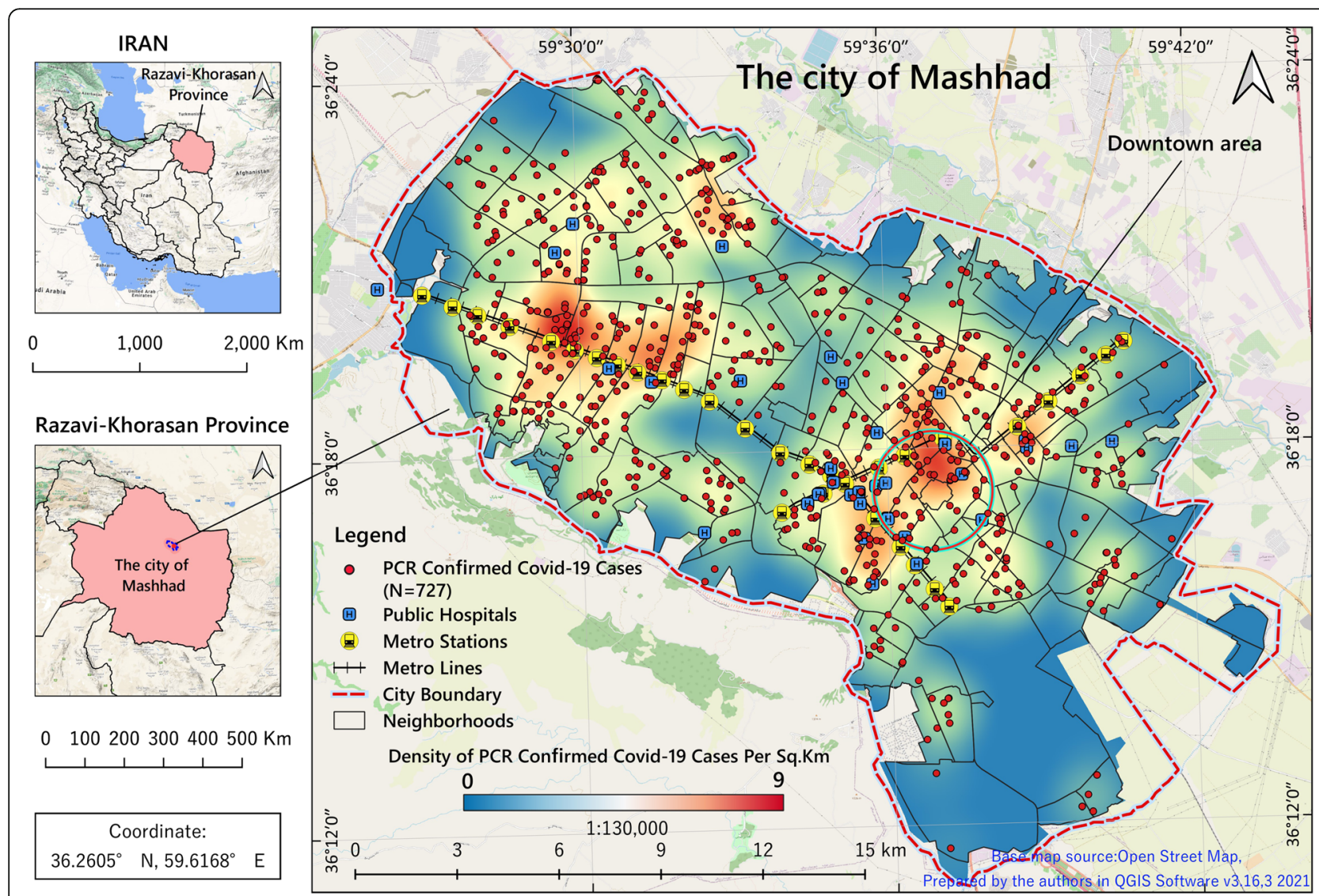

Fig. 1 Geographical location of the study area with the distribution of hospitals and PCR-confirmed COVID-19 cases. The figure was created by the authors using QGIS free software v.3.18.3 
laboratory tests. For unequivocal confirmation of this infection, a Reverse Transcription Polymerase Chain Reaction (RT-PCR) test is required [31]. The demographic and clinical database included patients' residence address, sex, age, date of symptoms onset, Length of Stay (LOS) in the hospital, underlying diseases, common symptoms, exposure history, disease severity and disease outcome.

\section{Statistical analysis}

At the first level, continuous variables were expressed as median and Inter Quartile Range (IQR) and testing the null hypothesis using the Mann-Whitney $U$ test. We used median and IQR because the data did not follow a normal distribution. Categorical variables were expressed as number and percentage and compared by Fisher's exact test $\left(\chi^{2}\right)$ between men and women as well as between survivors and non-survivors groups. To determine the effect of age, sex, ICU admission, LOS and comorbidities on mortality, univariate logistic regression was used. We also applied the un-adjusted Odds Ratio (OR) with a $95 \%$ Confidence Interval (CI). To do this, 2, 943 patients with a certified outcome (death or recovery) were included. All tests were two-sided with $p<0.05$ considered statistically significant. All statistical analyses were performed using $\mathrm{R}$ software, version 4.0.5 (R Foundation for Statistical Computing) and Microsoft Excel 2016.

\section{Spatiotemporal analyses and mapping techniques}

For this study, we only used a subdivision comprising those COVID-19 cases in Mashhad City that had been confirmed by RT-PCR $(n=727)$. Any data outside the city of Mashhad were excluded from the spatiotemporal approach. With the study area located around the $36^{\circ} \mathrm{N}$ and $59^{\circ} \mathrm{E}$, the WGS_1984_UTM_Zone_40N projection system was used for projecting the GIS layer. Five age groups including 0-14, 15-24, 25-44, 44-64, and $\geq 65$ years old were used to calculate the age- and sexadjusted incidence and mortality rates of the COVID-19 in each census tract. ArcGIS software, version 10.7.1 (ESRI, Redlands, CA, USA) was used for the spatial analysis.

\section{Kernel density estimation (KDE)}

$\mathrm{KDE}$, one of the non-parametric and distance-based techniques for analysing the spatial intensity of point occurrences, shows the locations with the highest or lowest density on a smooth density surface map. Here, the value of each cell at the raster (image file format) surface refers to the number of incidence events. In this study, we used a $30-\mathrm{m}$ cell size within a $2500-\mathrm{m}$ bandwidth displaying a smoothed spatial density map [32].

\section{Hotspot analysis (Getis-Ord Gi*)}

A hotspot is an area within a prescribed limit with concentration or dispersion of occurrences of the same value $[33,34]$. The Getis-Ord $\mathrm{Gi}^{*}$ statistics detects the presence of local spatial autocorrelations, i.e., hotspots, with calculations based on Z-score and $p$-value. We applied this statistic to identify COVID-19 hotspots and coldspots based on age- and sex-adjusted incidence rates at the census tract level as spatial features. The index is computed by the following equation:

$$
G_{i}^{*}=\frac{\sum_{j=1}^{n} w_{i, j} X_{j} \bar{X}-\sum_{j=1}^{n} w_{i, j}}{S \sqrt{\frac{\left[n \sum_{j=1}^{n} w_{i, j}^{2}-\left(\sum_{j=1}^{n} w_{i, j}\right)^{2}\right]}{n-1}}}
$$

Where $\mathrm{X}_{j}$ is the attribute value, COVID-19 incidence in this study, for feature $j ; \mathrm{w}_{i j}$ is the spatial weight between feature $i$ and $j ; \mathrm{n}$ is equal to the total number of features; $\bar{X}$ is the mean of the corresponding attribute and $S$ is the standard deviation of $\mathrm{X}_{j}$. The $\mathrm{G}_{i}{ }^{*}$ statistic is a $\mathrm{z}$-score, so no further calculations are required. Selecting the proper conceptualization relationships method is important to measure the $G_{i}{ }^{*}$ statistic. Among different methods of spatial conceptualization relationships, in this study, the Contiguity Edges Corners method was used for all calculations. This method is the most appropriate and effective method for polygonal features [35].

\section{Spatial autocorrelation}

There are various methods for measuring spatial autocorrelation. The global methods are more sensitive to departures from the null hypothesis (random distribution) but do not tell where the clusters are, which is possible when applying local methods. We used Global Moran's Index (GMI) [36] and Anselin's Local Moran's Index (ALMI) since they are generally more accurate concerning measuring autocorrelation than other statistics [36]. The value of GMI and ALMI vary between +1 and -1 . The ALMI can detect four types of clusters: High-High $(\mathrm{HH})$ reflecting high incidence areas surrounded by other high incidence areas, High-Low (HL) high incidence areas surrounded by low incidence areas, Low-Low (LL) low incidence areas surrounded by other low incidence areas, and Low-High (LH) low incidence areas surrounded by high incidence areas [37].

\section{End-points}

The end-point was in principle survival after infection and discharge from the hospital. We investigated this with regard to ICU admission, use of ventilators and coma taking into account gender, age, co-morbidities, 
symptoms and severity of the infection and the number of days counted from hospital admission to a certified outcome.

\section{Results}

\section{Statistical analysis}

Of the 4000 patients included in this study, 2352 (58.8\%) were males and 1648 (41.2\%) females. Table 1 shows a comprehensive comparison of the genders with respect to their responses to the infection, while Table 2 is focused on the health outcomes in those with evident health outcomes, i.e. survivors $(n=2236)$ and nonsurvivors $(n=707)$. We excluded all those continuing to receive care at the date of reporting $(n=1057)$ as the outcome was then unknown.

\section{Age and sex}

The median age of all patients was 57 years (IQR [39-71]). Seven percent (280 cases) were less than 20 years old and $43 \%$ (1720) older than 60 years. Women were slightly older than men ( 58 vs. 56 years of age) and had no significant differences in terms of common symptoms. However, as seen in Table 1, they had more often co-morbidities, such as Cardiovascular Diseases (CVD) (24.3\% vs. $17.2 \%)$, diabetes (14.5\% vs. 10.7\%) and Chronic Obstructive Pulmonary Diseases (COPD) $(7.3 \%$ vs. $4.9 \%),(p<0.05)$. More men $(n=2352,58.8 \%)$ than women $(n=1648,41.2 \%)$ were admitted because of COVID-19 symptoms to health centres and hospitals. Especially among the nonsurvivors, the ratio of men to women was $60.8 \%(n=430)$ to $39.2 \%(n=277)$.

\section{Symptoms}

In this study, 17 types of COVID-19 symptoms were reported. The most common were dyspnoea (69.4\%), cough (59.4\%), fever (54.4\%) and weakness (19.45\%). In order to clarify the prevalence of pre-existing medical conditions, we created combination charts (Fig. 2) that show the prevalence of symptoms and co-morbidities alone or combined. Figure 2a shows the rate of the four most common symptoms and various combinations in relation to survivors and non-survivors $(n=2943)$. As can be seen, approximately $82 \%$ of those who did not survive, suffered from dyspnoea, and $16.5 \%$ of them experienced this symptom without any combination with other symptoms. The most common combination of symptoms was the triple group of dyspnoea-cough-fever ( $23.5 \%$ mortality vs. $24.2 \%$ survival), followed by the dual combinations of dyspnoea-fever $(15.1 \%$ vs. $8.6 \%)$, dyspnoea-cough $(14.6,15.1 \%)$ and cough-fever (5.2, $10.8 \%)$. Only $0.6 \%$ of non-survivors and $2.5 \%$ of survivors had experienced the combination of cough-feverweakness which it means having these symptoms without suffering from shortness of breath was really rare.

\section{Co-morbidities}

Among the seven major underlying diseases, CVD $(20.1 \%)$, diabetes $(12.3 \%)$, COPD $(5.9 \%)$ and malignancies (2.5\%) were the most common in COVID-19 patients. All of those with underlying diseases, except liver disorders $(p=0.0953)$, showed higher rates in the non-surviving group vs. the surviving one $(p<0.05)$ (Table 2). Also, as shown in Fig. 2b, where the comorbidities and their combinations are presented in relation to survival. In this figure, the highest CFR was related to those who suffered from CVD (27.9\%) or diabetes $(18.1 \%)$ (including the combinations of these two co-morbidities). Out of those in the CFR group who had only one co-morbidity, CVD was the most common (14.9\%) followed by diabetes (7.6\%), COPD (4.7\%) and malignancy (3.9\%). The highest degree of the combined co-morbidities was CVD-diabetes $(8.1 \%$ mortality vs. $5.2 \%$ survival) and CVD-COPD (2.7\% mortality vs. $1.3 \%$ survival). In the category of three underlying diseases, the triple of CVD-diabetes-COPD had the highest mortality rate (1.6\%). Only one person (a male aged 72 years) experienced all four underlying diseases; against all odds, he survived.

\section{Patient outcomes}

The three types of outcomes in our data are telling. Overall, almost $56 \%(n=2236)$ of the patients were discharged in good condition, 17.7\% $(n=707)$ died and $26.5 \%(n=1057)$ were under continued care and thus deemed to have an equivocal outcome at the date of reporting (Table 1). Importantly, as seen in Table 2, the median age in the non-survivor group (68, IQR [59-79]) was 16 years above that of the survivors (52, IQR [36-66]), $(p<0.0001)$. By categorising the age into 10 categories (10-year intervals), as shown in Fig. 3, only $1 \%$ of all deaths $(7 / 707)$, occurred among the first three age groups ( $\leq 10,11-20$ and $21-30$ years of age). The highest frequency of COVID-19 infection was observed in the 51-60 age group (18.5\% (543/2943)). The chart shows clearly that the CFR rose with age in each of the four oldest age groups (61-70, 71-80, $81-90$ and $>90$ years) by reaching $35.8 \%$ (191/533), 38.0\% (150/394), 44.9\% (134/298) and $57.8 \%(26 / 45)$, respectively. It can thus be said that, in the current study, 71\% (501/707) of all CFRs caused by COVID-19 occurred in ages over 60 years.

\section{End-points}

Based on Table 2, more than $60 \%$ of the non-survivors were men. The use of ventilators for non-survivors (29.5\%) was almost twice that given for the survivors (15.2\%), and ICU admission was more than twice for those who died (21.2\%) compared to that for the survivors $(8.4 \%)$, both with a highly significant $p$-value $(p<$ $0.0001)$. Also, the number of people who experienced 
Table 1 Baseline characteristics by gender of all COVID-19 cases referred to healthcare centres in Mashhad City from Feb 14, to May 11, 2020

\begin{tabular}{|c|c|c|c|c|}
\hline Reference & All patients & Males & Females & $p$-value \\
\hline Number of patients (\%) & $4000(100)$ & $2352(58.8)$ & $1648(41.2)$ & \\
\hline Median age of the patients & 57.0 years & 56.0 years & 58.0 years & $0.0104^{*}$ \\
\hline Age range & $39.0-71.0$ & $39.0-70.0$ & $39.0-73.0$ & \\
\hline Days from onset to hospital admission & 2.0 & 2.0 & 2.0 & 0.9783 \\
\hline Range of days & $1.0-4.0$ & $1.0-4.0$ & $0.0-4.0$ & \\
\hline Days from hospital admission to outcome & 5.0 & 5.0 & 5.0 & 0.4751 \\
\hline Range of days & $2.0-8.0$ & $2.0-8.0$ & $2.0-8.0$ & \\
\hline Demographics \& clinical characteristics & Number (\%) & Number (\%) & Number (\%) & \\
\hline \multicolumn{5}{|l|}{ Co-morbidity } \\
\hline Diabetes & $491(12.27)$ & $252(10.71)$ & $239(14.50)$ & $0.0003^{*}$ \\
\hline CVD & 805 (20.12) & $404(17.2)$ & $401(24.3)$ & $<0.0001^{*}$ \\
\hline Liver disorders & $112(2.80)$ & $61(2.59)$ & $51(3.09)$ & 0.3444 \\
\hline CRD & $155(3.87)$ & $95(4.04)$ & $60(3.64)$ & 0.5206 \\
\hline Nervous diseases & $99(2.47)$ & $64(2.72)$ & $35(2.12)$ & 0.2314 \\
\hline COPD & $236(5.90)$ & $115(4.89)$ & $121(7.34)$ & $0.0011^{*}$ \\
\hline Malignancy (any) & $99(2.47)$ & $59(2.50)$ & $40(2.42)$ & 0.8706 \\
\hline \multicolumn{5}{|l|}{ Initial symptoms } \\
\hline Fever & $2177(54.42)$ & $1308(55.61)$ & 869 (52.73) & 0.0716 \\
\hline Cough & $2377(59.42)$ & $1383(58.80)$ & $994(60.31)$ & 0.337 \\
\hline Dyspnoea & $2777(69.42)$ & $1606(68.28)$ & $1171(71.05)$ & 0.0609 \\
\hline Weakness & 778 (19.45) & $452(19.21)$ & 326 (19.78) & 0.6574 \\
\hline Myalgia & $574(14.35)$ & $331(14.07)$ & $243(14.74)$ & 0.5507 \\
\hline Dizziness & $338(8.45)$ & $206(8.75)$ & $132(8.0)$ & 0.4020 \\
\hline Sore throat & $434(10.85)$ & $262(11.13)$ & $172(10.43)$ & 0.4819 \\
\hline Sputum & $74(1.85)$ & 37 (1.57) & $37(2.24)$ & 0.1206 \\
\hline Diarrhoea & $137(3.42)$ & 79 (3.35) & $58(3.51)$ & 0.7834 \\
\hline Nausea or vomiting & $332(8.30)$ & $182(7.74)$ & $150(9.10)$ & 0.1238 \\
\hline Headache & $325(8.12)$ & $184(7.82)$ & $141(8.55)$ & 0.4038 \\
\hline Chest pain & $318(7.95)$ & $181(7.70)$ & $137(8.30)$ & 0.4773 \\
\hline Abdominal pain & $70(1.75)$ & $32(1.36)$ & $38(2.30)$ & $0.0248^{*}$ \\
\hline Arthralgia & $235(5.87)$ & $133(5.65)$ & $102(6.19)$ & 0.4792 \\
\hline Pharyngitis & $49(1.22)$ & $27(1.14)$ & $22(1.33)$ & 0.5967 \\
\hline Conjunctivitis & $30(0.75)$ & $17(0.72)$ & $13(0.78)$ & 0.8117 \\
\hline Abnormal chest X-ray & $1059(26.47)$ & $617(26.23)$ & $442(26.82)$ & 0.6786 \\
\hline \multicolumn{5}{|l|}{ End-points } \\
\hline ICU admission & $502(12.55)$ & $307(13.05)$ & $195(11.83)$ & 0.2516 \\
\hline Ventilator & $772(19.30)$ & 449 (19.09) & $323(19.59)$ & 0.6878 \\
\hline Coma & $24(0.60)$ & $16(0.68)$ & $8(0.48)$ & 0.4322 \\
\hline \multicolumn{5}{|l|}{ Exposure history (last 14 days) } \\
\hline Travel & $83(2.07)$ & $58(2.46)$ & $25(1.51)$ & $0.0382^{*}$ \\
\hline Exposed at medical centres & $323(8.07)$ & $185(7.86)$ & $138(8.37)$ & 0.5615 \\
\hline Exposed to possibly infected individuals & $267(6.68)$ & $155(6.59)$ & $112(6.79)$ & 0.7973 \\
\hline Exposed to animals & $175(4.37)$ & $118(5.02)$ & $57(3.46)$ & $0.0177^{*}$ \\
\hline
\end{tabular}


Table 1 Baseline characteristics by gender of all COVID-19 cases referred to healthcare centres in Mashhad City from Feb 14, to May 11, 2020 (Continued)

\begin{tabular}{lllll}
\hline Reference & All patients & Males & Females & p-value \\
\hline Being healthcare staff & $281(7.03)$ & $158(6.71)$ & $123(7.46)$ & $\ldots .3636$ \\
Disease severity & $\ldots$ & $\ldots$ & $1301(78.94)$ & $0.0404^{*}$ \\
General & $3228(80.70)$ & $1927(81.93)$ & $334(20.27)$ & $\ldots$ \\
Severe & $748(18.70)$ & $414(17.60)$ & $13(0.79)$ & $\ldots$ \\
Critical & $24(0.60)$ & $11(0.47)$ & $\ldots$ & $\ldots .0437^{*}$ \\
Disease outcome & $\ldots$ & $\ldots$ & $277(16.8)$ & $\ldots$ \\
Non-survivor & $707(17.67)$ & $1334(56.7)$ & $902(54.7)$ & $\ldots$ \\
Survivor & $2236(55.90)$ & $588(25.0)$ & $469(28.5)$ & $\ldots$ \\
Ongoing care & $1057(26.43)$ & $\ldots$ & $\ldots$ & $\ldots$ \\
COVID-19 confirmation & $\ldots$ & $816(34.7)$ & $1536(65.3)$ & $1139(69.1)$ \\
PCR confirmation & $1325(33.1)$ & $2675(66.9)$ & $\ldots$ & $\ldots$ \\
Clinical confirmation & & $\ldots$ & $\ldots$ \\
\hline
\end{tabular}

CVD Cardiovascular Diseases, CRD Chronic Renal Diseases, COPD Chronic Obstructive Pulmonary Diseases, ICU Intensive Care Unit. *Significant values

coma was higher in the non-survivor group ( $p=0.0168)$. The median number of days counted from hospital admission to death or discharge was significantly different between the people who died (6 days, IQR [2-10]) and those who survived (4 days, IQR [2-7]). However, there was no significant difference between the time from symptom onset to hospital admission between these groups $(p=0.0695)$.

\section{History of exposure}

Of all cases, $7 \%(n=281)$ were healthcare staff, three of whom $(0.5 \%)$ died. The rate of exposure at medical centres, by meeting possibly infected individuals and/or animals were 8,7 and $4.3 \%$, respectively. Among the infected cases, men had travelled significantly more than women $(p<0.05)$.

\section{Admission trend}

As shown in Fig. 4, covering 3 months of hospital admissions concerning COVID-19 in the city of Mashhad, each admission peak was followed by a pair of discharge and mortality peaks, the former about three times higher than the latter.

\section{Risk factor analysis}

By including the COVID-19 variables in univariate logistic regression, we found that older age ( $\geq 60$ years) was associated with increased odds of death (Fig. 5). People belonging to this category had almost five times the vulnerability in this regard (OR: 4.7, CI [3.8-5.6]) compared to those under 60 years. Patients with malignancy (OR: 3.8, CI [2.4-6.0]), diseases of the nervous system (OR: 2.2, CI [1.4-3.6]) or COPD (OR: 2.2, CI [1.6-3.0]) also had higher odds of death. The univariate regression also revealed these odds increased along with the time of hospitalization on a daily basis (OR: 1.07, CI [1.051.09]). ICU admission was seen as another risk factor as it was associated with a threefold increase in the odds of death (OR: 2.9 CI [2.3-3.7]).

\section{Spatiotemporal analysis Disease spatiotemporal trends}

Figure 6 shows the spatiotemporal progression of the COVID-19 outbreak across eight 10-day periods (14 Feb to 9 May, 2020) based on the KDE results with the strength of incidence and mortality rates displayed by colour code. As can be seen in Fig. 6a, the infection spread within 3 weeks from a general low presence $(n=$ 13 ) in the third week of February to a peak with a strong focus in the downtown area in the south-eastern part of the city that was maintained for 3 weeks with the highest density (4 events per $\mathrm{km}^{2}, n=252$ ) around the end of the first week of March. Then the infection waves first subsided but soon resumed forming another focus in the north-western part of the city that held sway between 20 Mar and 8 Apr after which it gradually disappeared. Figure $6 \mathrm{~b}$ tell a different story; while there were no deaths in the first period, the second has a close resemblance with the first period of disease incidence Fig. 6a, possibly indicating that time between the onset of symptoms lasted between 1 and 2 weeks; on the other hand, we do not know if the events shown refer to the same persons. Still, the temporal lag is quite evident with mortality due to COVID-19 beginning on Feb 25, peaking between Mar 18 and 28 before subsiding. It is noteworthy that, the incidence and mortality of the infection gradually decreased in the downtown area from this date. Out of all investigated patients in the study area $(n=727), 205$ (28.2\%) did not survive and $66.8 \%$ of these cases were men. Finally, it can be stated that apart from the time progression no other parallel significant difference was found in terms of incidence and/or mortality in different 
Table 2 Baseline characteristics stratified by mortality and survival of patients with a certified outcome in Mashhad City from Feb 14, to May 11, 2020

\begin{tabular}{|c|c|c|c|c|}
\hline Reference & All patients & Non-survivors & Survivors & $p$-value \\
\hline Number of patients (\%) & $2943(100)$ & $707(24)$ & $2236(76)$ & \\
\hline Median age of the patients & 57.0 & 68.0 & 52.0 & $0.0001^{*}$ \\
\hline Age range & $40.0-71.0$ & $59.0-79.0$ & $36.0-66.0$ & \\
\hline Days from onset to hospital admission & 2.0 & 2.0 & 2.0 & 0.0695 \\
\hline Range of days & $1.0-4.0$ & $0.0-4.0$ & $1.0-4.0$ & \\
\hline Days from hospital admission to outcome & 5.0 & 6.0 & 4.0 & $<0.0001^{*}$ \\
\hline Range of days & $2.0-8.0$ & $2.0-10.0$ & $2.0-7.0$ & \\
\hline Demographics \& Clinical Characteristics & Number (\%) & Number (\%) & Number (\%) & \\
\hline Sex & $\cdots$ & $\cdots$ & $\cdots$ & 0.5832 \\
\hline Female & $1179(40.06)$ & $277(39.18)$ & $902(40.34)$ & $\ldots$ \\
\hline Male & $1764(59.94)$ & $430(60.82)$ & $1334(59.66)$ & $\ldots$ \\
\hline \multicolumn{5}{|l|}{ Co-morbidity } \\
\hline Diabetes & 405 (13.76) & $129(18.25)$ & $276(12.34)$ & $0.0001^{*}$ \\
\hline CVD & $614(20.86)$ & $197(27.86)$ & $417(18.64)$ & $<0.0001^{*}$ \\
\hline Liver disorders & $89(3.02)$ & $28(3.96)$ & $61(2.72)$ & 0.0953 \\
\hline CRD & $120(4.07)$ & $38(5.37)$ & $82(3.67)$ & $0.0453^{*}$ \\
\hline Nervous diseases & $69(2.34)$ & $28(3.96)$ & $41(1.83)$ & $0.0011^{*}$ \\
\hline COPD & $181(6.15)$ & $71(10.04)$ & $110(4.91)$ & $<0.0001^{*}$ \\
\hline Malignancy (any) & $73(2.48)$ & $39(5.51)$ & $34(1.52)$ & $<0.0001^{*}$ \\
\hline \multicolumn{5}{|l|}{ Initial symptoms } \\
\hline Fever & $1720(58.44)$ & $385(54.45)$ & $1335(59.70)$ & $0.0135^{*}$ \\
\hline Cough & $1874(63.67)$ & $378(53.46)$ & $1496(66.90)$ & $<0.0001^{*}$ \\
\hline Dyspnoea & $2111(71.72)$ & $579(81.90)$ & $1532(68.51)$ & $<0.0001^{*}$ \\
\hline Weakness & $533(18.11)$ & $122(17.25)$ & $411(18.38)$ & 0.4984 \\
\hline Myalgia & $429(14.57)$ & $71(10.04)$ & $358(16.01)$ & $<0.0001^{*}$ \\
\hline Dizziness & $247(8.39)$ & $80(11.31)$ & $167(7.47)$ & $0.0013^{*}$ \\
\hline Sore throat & $352(11.96)$ & $47(6.64)$ & 305 (13.64) & $<0.0001^{*}$ \\
\hline Sputum & $55(1.86)$ & $5(0.70)$ & $50(2.23)$ & $0.0088^{*}$ \\
\hline Diarrhoea & $101(3.43)$ & $16(2.26)$ & $85(3.80)$ & 0.0501 \\
\hline Nausea or vomiting & $246(8.36)$ & $39(5.51)$ & $207(9.26)$ & $0.0017^{*}$ \\
\hline Headache & $245(8.32)$ & $35(4.95)$ & $210(9.39)$ & $0.0001^{*}$ \\
\hline Chest pain & $223(7.57)$ & $49(6.93)$ & $174(7.78)$ & 0.2906 \\
\hline Abdominal pain & $39(1.32)$ & $3(0.42)$ & $36(1.61)$ & $0.0162^{*}$ \\
\hline Arthralgia & $176(5.98)$ & $25(3.53)$ & $151(6.75)$ & $0.0016^{*}$ \\
\hline Pharyngitis & $37(1.25)$ & $6(0.85)$ & $31(0.14)$ & 0.2633 \\
\hline Conjunctivitis & $18(0.61)$ & $2(0.28)$ & $15(0.72)$ & 0.1984 \\
\hline Seizure & $22(0.75)$ & $6(0.85)$ & $16(0.71)$ & 0.7203 \\
\hline Abnormal chest X-ray & $697(23.68)$ & $186(26.30)$ & $511(22.85)$ & 0.0596 \\
\hline \multicolumn{5}{|l|}{ End-points } \\
\hline ICU admission & $338(11.48)$ & $150(21.21)$ & $188(8.40)$ & $<0.0001^{*}$ \\
\hline Ventilator & 549 (18.65) & 209 (29.56) & $340(15.20)$ & $<0.0001^{*}$ \\
\hline Coma & $19(0.65)$ & $9(1.27)$ & $10(0.45)$ & $0.0168^{*}$ \\
\hline
\end{tabular}


Table 2 Baseline characteristics stratified by mortality and survival of patients with a certified outcome in Mashhad City from Feb 14, to May 11, 2020 (Continued)

\begin{tabular}{lllll}
\hline Reference & All patients & Non-survivors & Survivors & \multicolumn{1}{c}{$\boldsymbol{p}$-value } \\
\hline Disease severity status & $\ldots$ & $\ldots$ & $\ldots$ & $0.0033^{*}$ \\
General & $2418(82.16)$ & $551(77.93)$ & $1867(83.50)$ & $\ldots$ \\
Severe & $503(17.09)$ & $150(21.22)$ & $353(15.78)$ & $\ldots$ \\
Critical & $22(0.75)$ & $6(0.85)$ & $16(0.72)$ & $\ldots$ \\
\hline
\end{tabular}

CVD Cardiovascular Diseases, CRD Chronic Renal Diseases, COPD Chronic Obstructive Pulmonary Diseases, ICU Intensive Care Unit. *Significant values

parts of the city. What is clear is that the mortality in the central and western parts of the city was higher than in other areas.

\section{Age- and sex-adjusted rates}

Figure 7a shows the sex- and age-adjusted incidence rates map (per 100,000 persons). According to this, the census tracts in the Central Business District (CBD), the western and the north-western parts of the city $(17.5 \%)$ experienced a high incidence (> 54.31 per 100,000 persons). Figure $7 \mathrm{~b}$, which presents the spatial pattern of mortality, showed a similar picture, but only $4.2 \%$ of the census tracts experienced high number of deaths

\section{Hotspot analysis}

The outcome of the Getis Ord $\mathrm{Gi}^{*}$ statistic is shown in Fig. 7c. Here, 24 census tracts in the north-western and downtown parts of the city showed COVID-19 hotspots (with 99, 95, and $90 \%$ confidence). Regarding the spatial pattern of mortality, as shown in Fig. 7d, 15 census tracts formed hotspots. The north-western region can be described as a combination of industrial and residential land use close to rural areas with low population density. The CBD area was extremely significant with respect to risk (hotspot point with 99\% confidence), which can be due to commercial and pilgrimage situations.

\section{Cluster and outlier analysis}

The GMI results for incidence and mortality were $0.072(z=$ $5.38, p=0.001)$, and $0.027(z=3.85, p=0.001)$, respectively, which indicated that the COVID-19 distribution was more spatially clustered than expected if the underlying spatial processes were random $(p=0.001)$. In other words, high-risk areas were surrounded by neighbours with high incidence risk. In order to determine how the incidence and mortality rates were clustered in the city, the ALMI was calculated. According to Fig. 7e, there was a bit of spatial autocorrelation of the COVID-19 epidemic incidence among the 1174 census tracts. In terms of incidence rates, we identified $\mathrm{H}-\mathrm{H}$ clusters (29 tracts), mainly in the central and north-western parts of the city which showed spatial autocorrelation $(p<$ 0.05 ). Only one census tract to the west in the city had an $\mathrm{H}-\mathrm{H}$ cluster. However, the L-L clusters (17 tracts) showed a spatial autocorrelation in the eastern regions $(p<0.05)$, while the $\mathrm{H}-\mathrm{L}$ and $\mathrm{L}-\mathrm{H}$ outliers were dispersed throughout the city. According to Fig. 7f, there were no spatial COVID-19 mortality clusters among the 1160 census tracts $(p>0.05)$. In addition, the clustered mortality pattern differed substantially from that of the incidence rates since the $\mathrm{L}-\mathrm{L}$ death rate values were statistically not significant and not clustered. But spatially, just as the incidence rates, the central and northwestern areas were clustered with high values $(p<0.05)$. In both the incidence and mortality maps, the $\mathrm{H}-\mathrm{L}$ outliers were located next to each other in downtown $(p<0.05)$.

\section{Discussion}

To the best of our knowledge, this is the first retrospective study conducted in Mashhad City with a simultaneous focus on statistical and spatiotemporal analysis. Our results show a mortality rate of $17.7 \%$ and the median age of patients was higher than that found in Chinese and Australian studies [37, 71], but lower compared to American and European reports [8, 38]. In accordance with most other studies [8,39-41], infected women were found to be slightly older than men in our study (2 years on average). We also found the most frequent COVID-19 infections (36.6\%) occurring in the 51-60 and 61-70 age groups (Fig.3), findings closely in line with studies conducted in Italy and China $[42,43]$. However, in contrast to studies in other countries [8, 38, 44], the frequency of infection in younger age groups (31-40 and 41-50) in our study was considerable (25.2\%), a fact that could be due to the lower median age of the Iranian population, which means that a larger proportion of younger people in Iran compared to many other countries are exposed in their daily activities [45]. Following the studies comparing the characteristics of survivors and non-survivors of COVID-19 patients [6, 7, 46, 47], we also found those who did not survive were on average much older than those who did. The CFR in elderly patients (age $\geq 60$ ) investigated by OR was almost five times more than the younger patients, indicating that senility might be a risk factor for mortality. This is hardly surprising as older patients are more vulnerable to serious complications due to a less active immune system and, particularly because they commonly have various underlying diseases. In order to predict poor prognosis in these patients, Ma et al.'s [48] suggested 


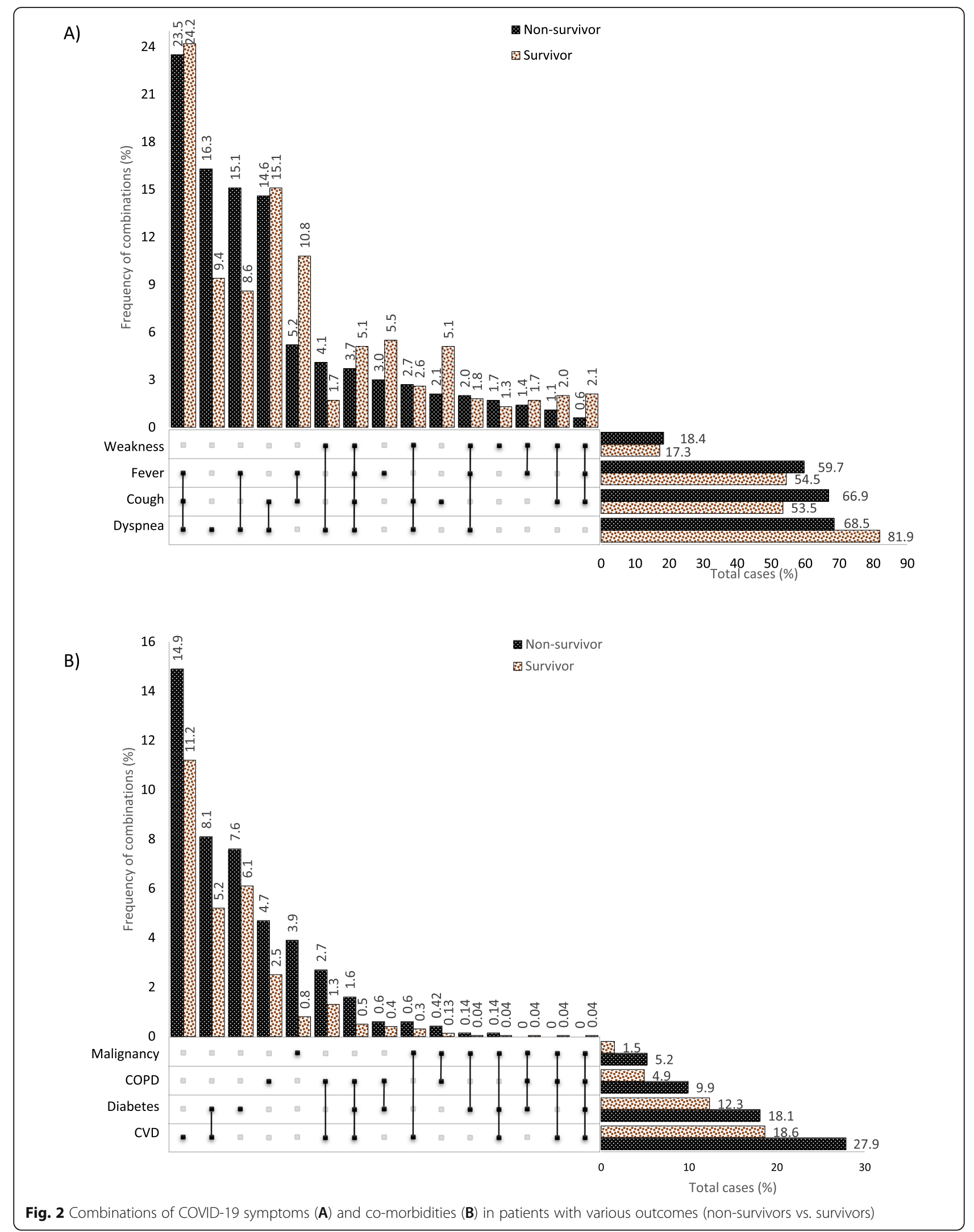




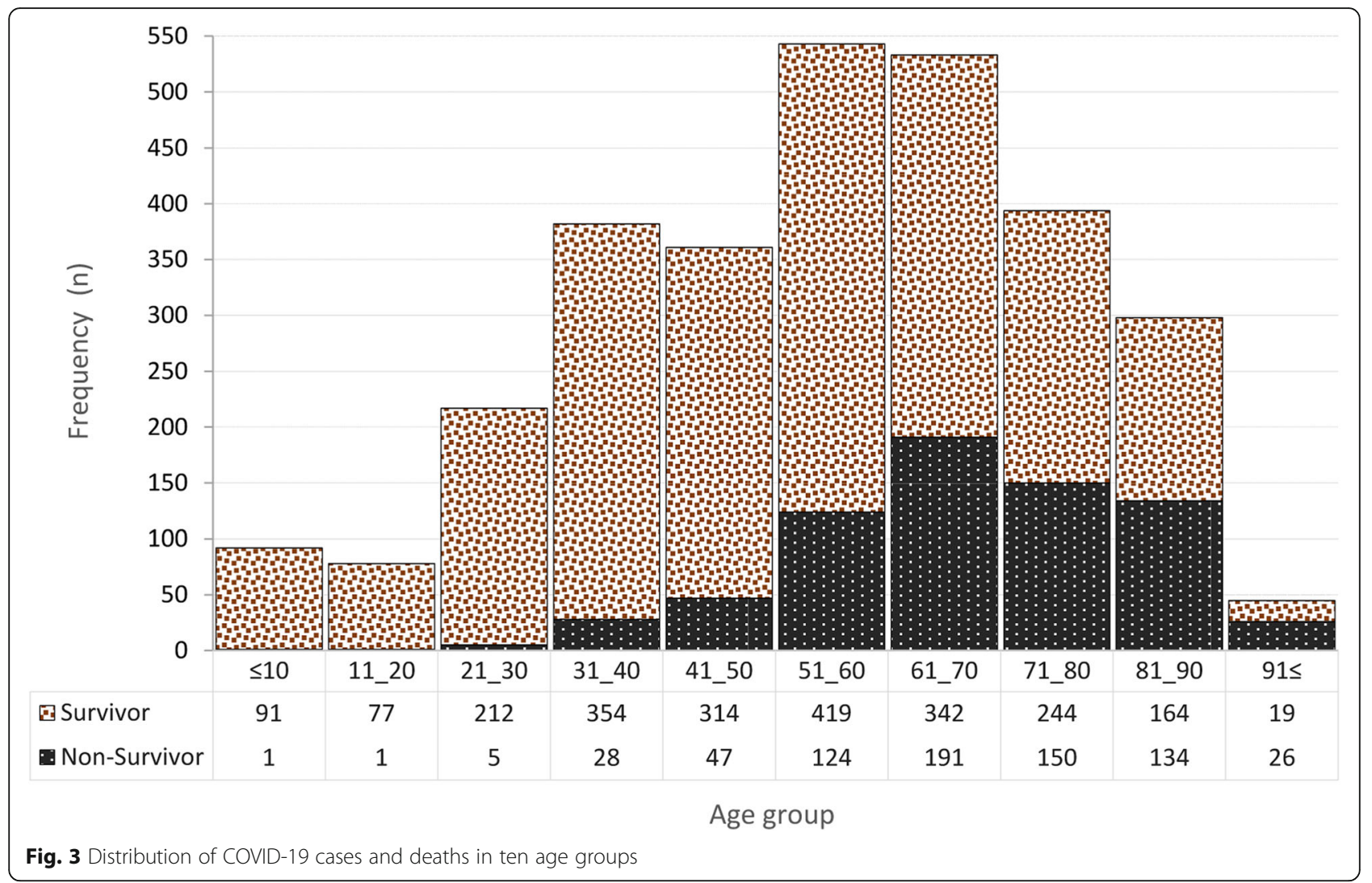

frailty assessment in the early stage of disease, which could help to identify potentially severe pneumonia.

The findings related to pre-existing medical conditions are in line with Emami et al.'s study [45], which reviewed the prevalence of underlying diseases in COVID-19 cases. As seen in Table 2, all investigated comorbidities, except liver disorders, were significantly higher more common in non-survivors compared to those who survived $(p<0.05)$. Although most studies $[6,46,47]$ show a higher prevalence of underlying diseases in the deceased patients, all did not find any significant differences regarding the prevalence of co-morbidities in nonsurvivors compared to survivors [7, 10]. However, although there is a high variability of the prevalence rates for CVD (7.5-40.0\%) and diabetes (8.0-38.0\%), it is well-known that these maladies are the most prevalent pre-existing medical conditions among COVID-19 patients $[5,6,8,10,11,39,43,46,49]$. As shown on the upper side of Fig. 2b, CVD was unaccompanied with any other co-morbidity in nearly $15 \%$ of those who died in

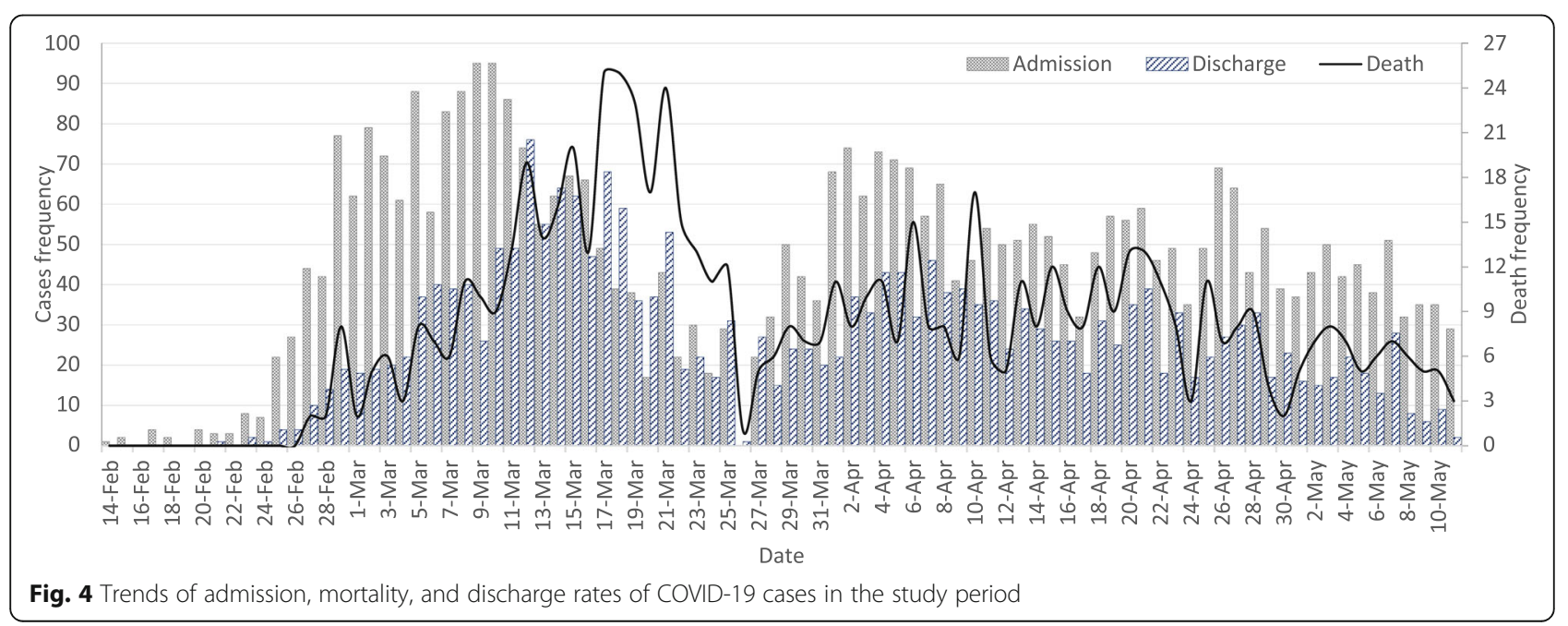




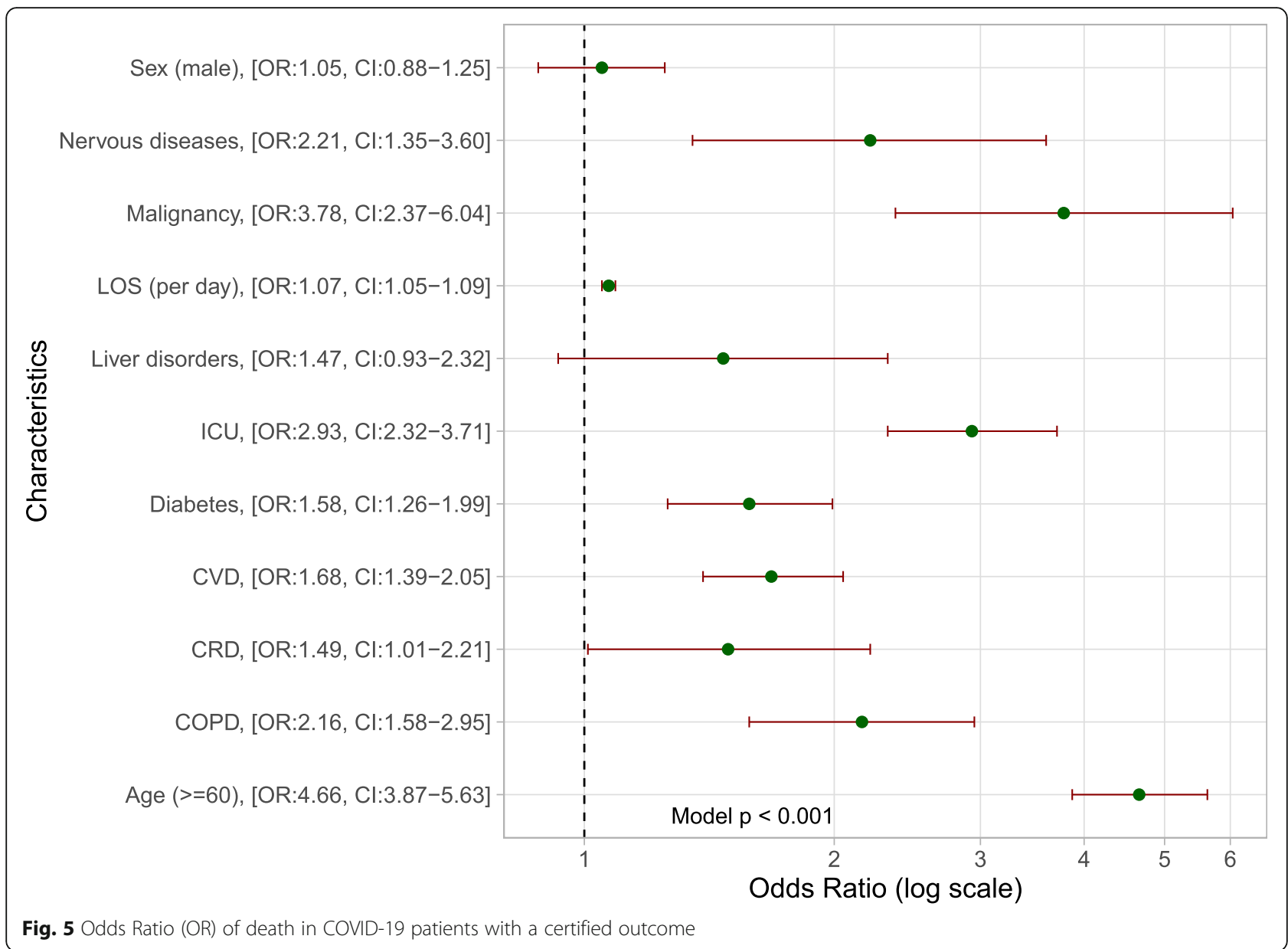

Mashhad, which indicates that CVD is a serious condition that potentially can lead to the poor prognosis of COVID-19 [50, 51]. The suggestion that can be made considering this high risk for CVD patients is the use of tele-rehabilitation, which has been well proven in previous studies [52, 53]. In agreement with our results, a nationwide analysis conducted in England has shown that diabetes (both types) is associated with a significantly increased CFR by COVID-19 [54]. Our results revealed that patients with malignancies also have a much higher risk, which increases the CFR almost four times. Immunosuppressive therapies and intrinsic frailty are possibilities that potentially put this population at risk [46].

According to the results of a meta-analysis [55] and the report from the Centres for Disease Control and Prevention (CDC) in the US [56], fever, cough, dyspnoea and fatigue are the most commonly manifested symptoms in COVID-19 patients. Regardless of the order, our findings agree with this. We found a significant difference in the frequency of main manifested symptoms between the deceased and the survivors (Table 2), this difference was not significant in other studies [6, 47]. Fever has been reported as the most common symptom in most studies [5, 6, 11, 12, 39, 57], while others, similar to our results (70\%), report dyspnoea as the most common symptom $[47,58,59]$. As shown, the combination of dyspnoea-cough-fever was the most commonly manifested symptom among the patients who did not survive (23.5\%) (Fig. 2a). Since $82 \%$ of deceased patients had dyspnoea as one of the manifested symptoms and also $16.5 \%$ of them reported it as the only symptom of disease, it can be claimed that suspicious cases presenting with this symptom should be taken seriously even if it is the sole symptom.

In agreement with the results of other studies $[6,7,9-$ $11,46]$, our results showed that COVID-19 infects males more often than females (Table 1). However, contrary to our finding that the CFR in the male sex was not significantly higher than that in the female (OR: 1.05, CI [0.88-1.25], a majority of studies maintain that sex may influence mortality due to COVID-19 $[5,8,9]$. This is an important finding that must be further studied.

In contrast to reports in influential journals $[8,38]$ claiming that mechanical respiration results in very high CFRs, our study found only a 38\% (209/549) mortality in patients receiving mechanical ventilation due to 


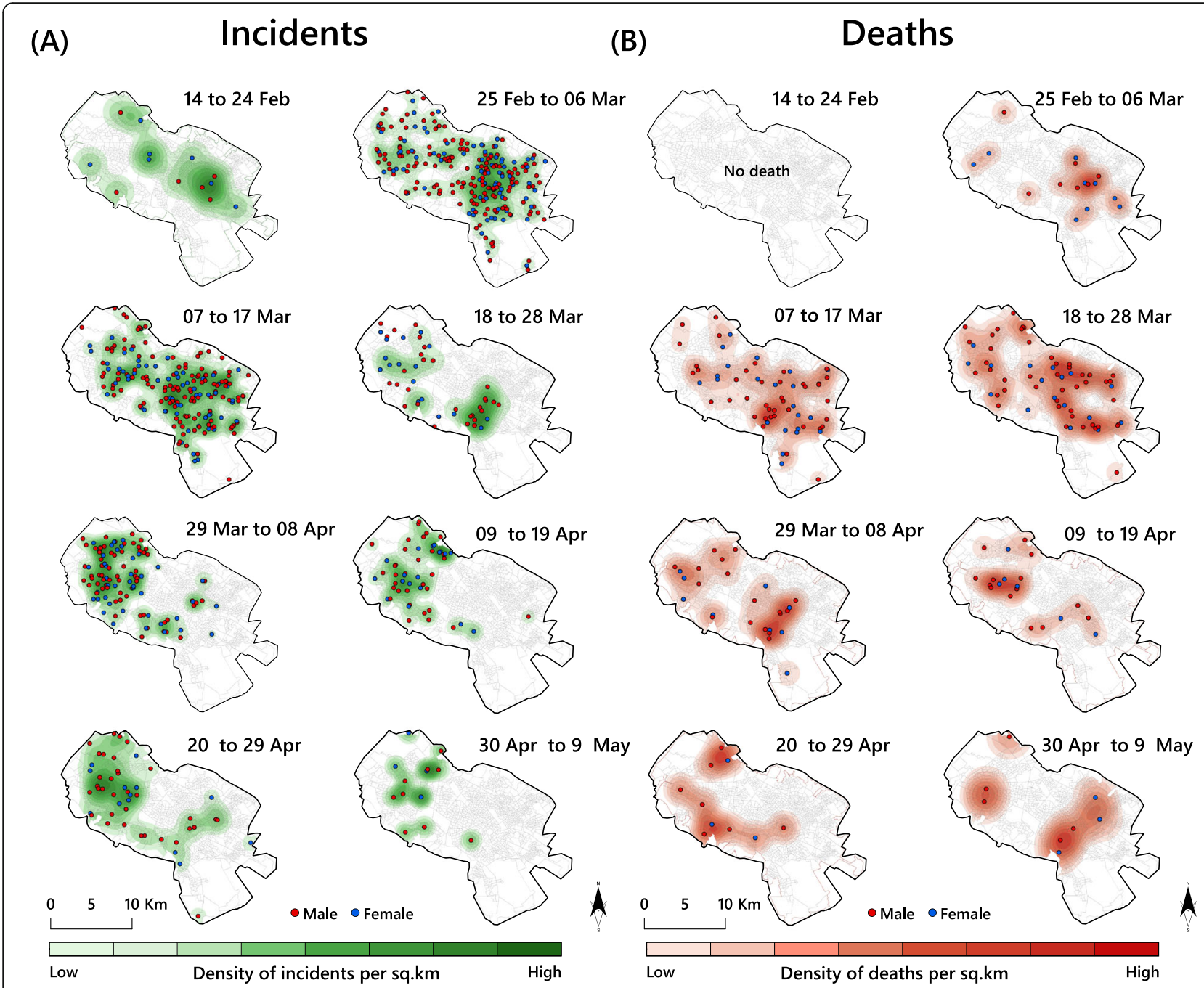

Fig. 6 Spatiotemporal patterns of confirmed COVID-19 cases, across eight time periods (A) Incidence; (B), Mortality (expressed as the number of cases per $\mathrm{km}^{2}$ ). The figure was created by the authors using ArcGIS v.10.8. A correct license was attributed by the authors

COVID-19 induced shortness of breath. However, we found admission to an ICU as a risk factor that increased the CFR up to three times. The median duration of symptoms manifestation before admission was 2 days, i.e. slightly lower than that of English patients (4 days, IQR [1-8]) and much lower than that of Chinese patients (11 days, IQR [8-14]) [6, 8]. The 5-day median LOS in our study agrees quite well with that by Richardson et al. [38] (4 days, IQR [2-7]), but it was less than half of that in Bhatraju et al.'s study [58] (12 days, IQR [8-18]). It is noteworthy that, based on the results of regression analysis, increased LOS values are associated with higher CFRs. The relatively low LOS rate in our study may be due to the sudden increase of infected patients leading to a shortage of medical equipment and active hospital beds at the early stages of the COVID-19 pandemic in Iran.
Lockdown of cities can be a great solution to control and prevent the spread of the disease [60-62]. In Iran, the lack of public awareness promoted the rapid spread of COVID-19 and the rate of hospital admission and mortality increased dramatically. However, by raising public awareness about the seriousness of the COVID19 threat, imposing travel restrictions and closing schools and universities as mentioned by other studies $[63,64]$ as an effective factor in reducing the burden of COVID-19, the first peak of the outbreak was eventually largely controlled (Fig. 4). But perhaps the most important factor in this control was the annual Iranian Nowruz two-week holiday. Starting on March 20, it turned out to be a useful excuse for a national lockdown, e.g., already on March 14, 1 week before the holiday, the largest commercial and pilgrimage centre in the CBD of the city was closed due to the outbreak of COVID-19. This 


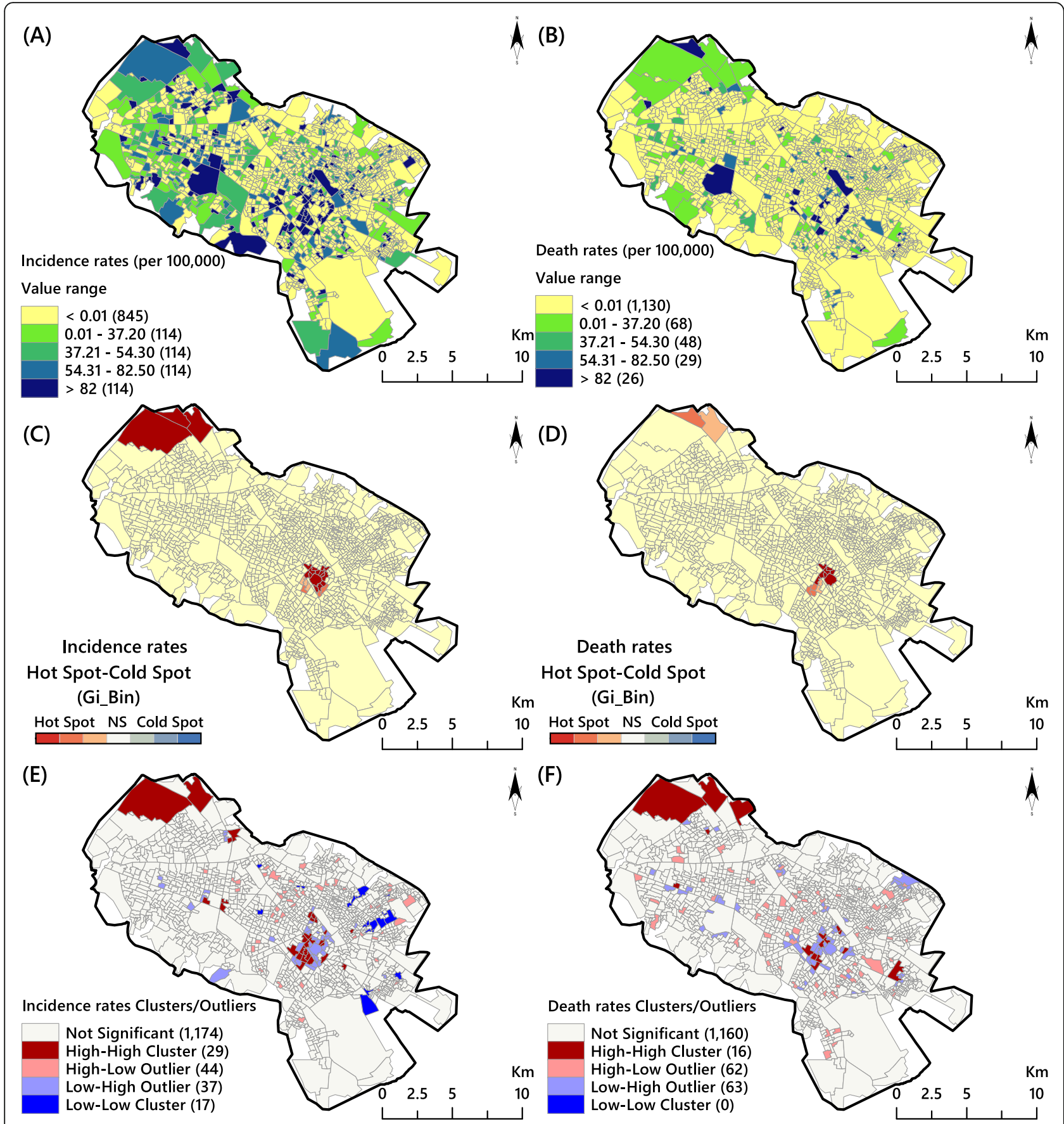

Fig. 7 The maps of COVID-19 spatial analysis results: A-Incidence rates, B-Death rates, C-Incidence Hot-spots, D- Death Hot-spots, E-Incidence Cluster/Outlier, F- Death Cluster/Outlier. The figure was created by the authors using ArcGIS v.10.8. A correct license was attributed by the authors

shows that a timely urban policy can be very effective. But due to the economic fragility of the Iranian community, the closure of the central parts of the cities cannot be sustained for the longer term. Due to the complex nature of the COVID-19, short-term temporal and spatial policies can fail. Hence, more efficient space-time policies are needed.
Using hotspot analysis, we identified statistically significant transmission areas in terms of the spatial autocorrelation of COVID-19 incidence and deaths in the two prominent areas of the city characterized by high traffic and interchange, i.e. the central part of the city or CBD and the industrial area in north-western Mashhad. The number and density of pilgrimage, commercial, and 
tourist services centres (as well as hotels and inns) are high in the former, while the latter consists of industrial areas surrounded by rural areas from where large numbers of people commute to work. In addition, as concluded in Mazar et al.'s study [26], in the frequently visited cities where travel back and forth is high and permanent, the prevalence of the COVID-19 is also high. Figure 1 reveals that the density of infected people living in areas close to metro lines was much higher than the rest of the city. Accordingly, as proven in the previous studies [65-68], in congested places such as business centres and public transportation, a quicker spread of the virus is expected. In agreement with the findings of Pourghasemi et al. [69], it can be concluded that the areas considered public spaces of the city (such as subway stations, parks, commercial areas, and pilgrimage centres) are high-risk areas since adherence to health protocols there has been weaker than in the residential areas. However, we should not forget that the marginal areas (e.g. north-western areas) of the city have less potential accessibility compared with central urban, due to the high density of hospitals and other health care centres [15, 70, 72]. Most of these neighbourhoods are low-income parts of the city and they are very vulnerable to the pandemic.

The downtown of Mashhad is no exception from other areas with a high prevalence of COVID-19 cases, but in line with the points made by Pourghasemi et al. [69], it presents a multitude of places where high transmission of the virus can occur. Because the COVID-19 infection did not necessarily form hotspots only where the population density is high in our study, the results of the current study are neither are in line with the findings of Tang et al. [21], who showed the hotspots where the virus originated in China nor do they correspond to the findings of Fan et al. [22], who found the hotspots to be mainly restricted to densely populated or developed areas. Accordingly, we instead found it useful to follow other patterns and variables in each district of the city, such as the household's socioeconomic status, urban built environment and air quality index. As the spatiotemporal maps show (Fig. 6), we found the spatiotemporal pattern of the COVID-19 to be very dynamic and unpredictable, which is in agreement with the findings of Arauzo-Carod [25]. Indeed, in agreement with other spatial studies [23, 24] on COVID-19 distribution and trends, we found that the spatial patterns of the infection in the city of Mashhad were clustered rather than random. Identifying such clusters over time would help urban health planners to implement tailored lockdown strategies. For example, $\mathrm{HH}$ and $\mathrm{HL}$ areas should be lock downed first (Fig. 7).

\section{Limitations}

Only 33\% of all included cases were approved by RTPCR testing and the rest of the cases were clinically confirmed. This is because of the retrospective study design and including a large number of COVID-19 cases. Interestingly, however, the obtained results were in line with other studies. The presence of such data can make the results more generalizable. As previously shown in other studies, hypertension affects the prognosis of the COVID-19 patients negatively, but we had no separate data about it and it was therefore collected under the heading CVD. As well as, the absence of data on patients who were still hospitalized at the time of reporting may have biased the findings. In order to address these types of data deficiencies in the future, using structured forms for clinical data gathering and also developing registry programs are highly recommended [73]. Due to the short period (3 months) covered, the advantages of spatial analysis cannot tell us more now. The spatial and temporal dynamics of the disease need to be studied over a longer period in order to provide more effective solutions. However, due to our discovery of hotspots and coldspots, city policymakers can concentrate their solutions in the central, eastern, and north-eastern parts of the city. In particular, central sectors need more sustainable solutions. Finally, it was possible that some patients had not gone to the hospitals, thus we did not have their data.

\section{Conclusions}

Older adults and people with severe underlying medical conditions are at higher risk for developing complications from COVID-19 infection. By applying spatiotemporal methods to identify the transmission trends and clustering patterns of the disease, we expect the current study to improve our understanding of which factors are of practical importance for transmission of the disease thereby providing documentation that can assist policymakers. In response to the COVID-19 epidemic, along with efforts to find medical solutions, future studies should focus on predicting disease recurrence in cities and places where people tend to aggregate. Medical studies should be conducted in conjunction with socioeconomical, spatial, and environmental studies to provide comprehensive and integrated solutions to control and prevent epidemic diseases in general.

\footnotetext{
Abbreviations

SARS-CoV-2: Severe Acute Respiratory Syndrome Coronavirus 2; ICU: Intensive Care Units; WHO: World Health Organization; SOFA: Sequential Organ Failure Assessment Score; GISs: Geographic Information Systems; RT-PCR: Reverse Transcription Polymerase Chain Reaction; LOS: Length of Stay; MUMS: Mashhad University of Medical Sciences; IQR: Inter Quartile Range; OR: Odds Ratio; Cl: Confidence Interval; KDE: Kernel Density Estimation; GMI: Global Moran's Index; ALMI: Anselin's Local Moran's Index; CVD: Cardiovascular Diseases; CRD: Chronic Renal Diseases; COPD: Chronic Obstructive Pulmonary Diseases; CBD: Central Business District; $\mathrm{HH}$ : HighHigh; HL: High-Low; LL: Low-Low; LH: Low-High; CDC: Centre for Disease Control and Prevention; CFR: Case Fatality Rate
} 


\section{Acknowledgments}

We would like to thank Mashhad University of Medical Sciences for funding this study.

\section{Authors' contributions}

SM and AM drafted the first version of the manuscript. SM, AM, BK and EP performed statistical and spatial analyses and interpreted all the results. SM, $\mathrm{RB}$, and BK critically revised the paper. FD, MO and AT contributed to data gathering and geocoding. BK was the principal investigator and the research leader. The author(s) read and approved the final manuscript.

\section{Funding}

This study was financially funded by Mashhad University of Medical Sciences (fund number: 990253). Furthermore, the university provided the data of COVID-19 patients

\section{Availability of data and materials}

The datasets used and/or analysed during the current study are publicly available from the corresponding authors on request.

\section{Declarations}

\section{Ethics approval and consent to participate}

The study was approved by the ethical committee of Mashhad University of Medical Sciences with the reference number IR.MUMS.REC.1399.215.

\section{Consent for publication}

Not applicable.

\section{Competing interests}

None reported.

\section{Author details}

${ }^{1}$ Department of Medical Informatics, School of Medicine, Mashhad University of Medical Sciences, Mashhad, Iran. ${ }^{2}$ Student Research Committee, Mashhad University of Medical Sciences, Mashhad, Iran. ${ }^{3}$ Department of Geography and Urban Planning, Faculty of Social Sciences, University of Mohaghegh Ardabili, Ardabil, Iran. ${ }^{4}$ Ingerod, Brastad, Sweden. ${ }^{5}$ (Formerly with the UNICEF/ UNDP/World Bank/WHO Special Program for Research and Training in Tropical Diseases, World Health Organization), Geneva, Switzerland. ${ }^{6}$ Department of Microbiology and Virology, School of Medicine, Mashhad University of Medical Sciences, Mashhad, Iran. ${ }^{7}$ Department of Anaesthesiology, School of Medicine, Shahid Sadoughi University of Medical Sciences, Yazd, Iran. ${ }^{8}$ Department of Emergency Medicine, Faculty of Medicine, Sabzevar University of Medical Sciences, Sabzevar, Iran. ${ }^{9}$ Department of Human Geography and Logistics, Faculty of Earth Science, Shahid Beheshti University, Tehran, Iran. ${ }^{10}$ Department of Medical Informatics, School of Medicine, Mashhad University of Medical Sciences, Mashhad, Iran.

Received: 23 November 2020 Accepted: 18 June 2021

Published online: 12 July 2021

\section{References}

1. Bergquist R, Kiani B, Manda S. First year with covid-19: assessment and prospects. Geospat Health. 2020;15:187-90.

2. Shuja KH, Aqeel M, Jaffar A, Ahmed A. COVID-19 pandemic and impending global mental health implications. Psychiatr Danub. 2020;32(1):32-5. https:// doi.org/10.24869/psyd.2020.32.

3. Zhu N, Zhang D, Wang W, Li X, Yang B, Song J, et al. A novel coronavirus from patients with pneumonia in China, 2019. N Engl J Med. 2020;382(8): 727-33. https://doi.org/10.1056/NEJMoa2001017.

4. Su Z, McDonnell D, Cheshmehzangi A, Abbas J, Li X, Cai Y. The promise and perils of unit 731 data to advance COVID-19 research. BMJ Glob Health. 2021;6(5):e004772. https://doi.org/10.1136/bmjgh-2020-004772.

5. Suleyman G, Fadel RA, Malette KM, Hammond C, Abdulla H, Entz A, et al. Clinical characteristics and morbidity associated with coronavirus disease 2019 in a series of patients in metropolitan Detroit. JAMA Netw Open. 2020; 3(6):e2012270. https://doi.org/10.1001/jamanetworkopen.2020.12270.

6. Zhou F, Yu T, Du R, Fan G, Liu Y, Liu Z, et al. Clinical course and risk factors for mortality of adult inpatients with COVID-19 in Wuhan, China: a retrospective cohort study. Lancet. 2020;395(10229):1054-62. https://doi. org/10.1016/S0140-6736(20)30566-3.

7. Li K, Chen D, Chen S, Feng Y, Chang C, Wang Z, et al. Predictors of fatality including radiographic findings in adults with COVID-19. Respir Res. 2020; 21(1):146. https://doi.org/10.1186/s12931-020-01411-2.

8. Docherty AB, Harrison EM, Green CA, Hardwick HE, Pius R, Norman L, et al. Features of 20133 UK patients in hospital with covid-19 using the ISARIC WHO clinical characterisation protocol: prospective observational cohort study. BMJ. 2020;369:m1985

9. Nikpouraghdam M, Jalali Farahani A, Alishiri G, Heydari S, Ebrahimnia M, Samadinia $\mathrm{H}$, et al. Epidemiological characteristics of coronavirus disease 2019 (COVID-19) patients in IRAN: A single center study. J Clin Virol. 2020; 127:104378. https://doi.org/10.1016/j.jcv.2020.104378.

10. Shahriarirad R, Khodamoradi Z, Erfani A, Hosseinpour H, Ranjbar K, Emami Y, et al. Epidemiological and clinical features of 2019 novel coronavirus diseases (COVID-19) in the south of Iran. BMC Infect Dis. 2020;20(1):427. https://doi.org/10.1186/s12879-020-05128-x.

11. Chen N, Zhou M, Dong X, Qu J, Gong F, Han Y, et al. Epidemiological and clinical characteristics of 99 cases of 2019 novel coronavirus pneumonia in Wuhan, China: a descriptive study. Lancet. 2020;395(10223):507-13. https:// doi.org/10.1016/S0140-6736(20)30211-7.

12. Wu C, Chen X, Cai Y, Xia J, Zhou X, Xu S, et al. Risk factors associated with acute respiratory distress syndrome and death in patients with coronavirus disease 2019 pneumonia in Wuhan, China. JAMA Internal Med. 2020;180: 934-43.

13. COVID Live Update: $175,341,392$ Cases and 3,780,433 Deaths from the Coronavirus - Worldometer. https://www.worldometers.info/coronavirus/. Accessed 10 June 2021

14. Artz M. GIS and pandemic influenza planning and response. GIS Sci. 2009; https://gisandscience.com/2009/11/16/gis-and-pandemic-influenza-pla nning-and-response/. Accessed 31 July 2020.

15. Hashtarkhani S, Kiani B, Bergquist R, Bagheri N, VafaeiNejad R, Tara M. An age-integrated approach to improve measurement of potential spatial accessibility to emergency medical services for urban areas. Int J Health Plann Manag. 2020;35(3):788-98. https://doi.org/10.1002/hpm.2960.

16. Kiani B, Raouf Rahmati A, Bergquist R, Hashtarkhani S, Firouraghi N, Bagheri $\mathrm{N}$, et al. Spatio-temporal epidemiology of the tuberculosis incidence rate in Iran 2008 to 2018. BMC Public Health. 2021;21(1):1093. https://doi.org/10.11 86/s12889-021-11157-1.

17. Rahmati AR, Kiani B, Afshari A, Moghaddas E, Williams M, Shamsi S. Worldwide prevalence of Anisakis larvae in fish and its relationship to human allergic anisakiasis: a systematic review. Parasitol Res. 2020;119(11):3585-94. https://doi.org/10.1007/s00436-020-06892-0.

18. Local Burden of Disease HIV Collaborators. Mapping subnational HIV mortality in six Latin American countries with incomplete vital registration systems. BMC Med. 2021;19:4.

19. Franch-Pardo I, Napoletano BM, Rosete-Verges F, Billa L. Spatial analysis and GIS in the study of COVID-19. A review. Sci Total Environ. 2020;739:140033.

20. Mousavi SH, Zahid SU, Wardak K, Azimi KA, Hosseini SMR, Wafaee M, et al. Mapping the changes on incidence, case fatality rates and recovery proportion of COVID-19 in Afghanistan using geographical information systems. J Clean Prod. 2020;51(6):600-2. https://doi.org/10.1016/j.arcmed.202 0.06 .010 .

21. Tang WL. The changing patterns of coronavirus disease 2019 (COVID-19) in China: A Tempogeographic analysis of the severe acute respiratory syndrome coronavirus 2 epidemic. Clin Infect Dis. 2020;71(15):818-24. https://doi.org/10.1093/cid/ciaa423.

22. Fan J, Liu X, Pan W, Douglas MW, Bao S. Epidemiology of coronavirus disease in Gansu Province, China, 2020. Emerg Infect Dis. 2020;26(6):125765. https://doi.org/10.3201/eid2606.200251.

23. Xiong $Y$, Wang $Y$, Chen F, Zhu M. Spatial statistics and influencing factors of the COVID-19 epidemic at both prefecture and county levels in Hubei Province, China. Int J Environ Res Public Health. 2020;17(11). https://doi. org/10.3390/ijerph17113903.

24. Murugesan B, Karuppannan S, Mengistie AT, Ranganathan M, Gopalakrishnan G. Distribution and trend analysis of COVID-19 in India: geospatial approach. J Geographic Stud. 2020;4(1):1-9. https://doi.org/10.21 523/gcj5.20040101.

25. Arauzo-Carod J-M. A first insight about spatial dimension of COVID-19: analysis at municipality level. J Public Health. 2020:43(1):98-106. https://doi. org/10.1093/pubmed/fdaa140. 
26. Arab-Mazar Z, Sah R, Rabaan AA, Dhama K, Rodriguez-Morales AJ. Mapping the incidence of the COVID-19 hotspot in Iran - implications for Travellers. Travel Med Infect Dis. 2020;34:101630. https://doi.org/10.1016/j.tmaid.2020.1 01630.

27. Worldometer. Iran Population (2020) - https://www.worldometers.info/ world-population/iran-population/. Accessed 13 Sept 2020

28. Bazzaz MM, Zarifian A, Emadzadeh M, Vakili V. Driving behaviors in Iran: a descriptive study among drivers of Mashhad City in 2014. Global J Health Sci. 2015;7:39

29. Ebrahim SH, Memish ZA. COVID-19-the role of mass gatherings. Travel Med Infect Dis. 2020;34:101617. https://doi.org/10.1016/j.tmaid.2020.101617.

30. SCl. Official report of statistical survey of population in Mashhad city archived by the Statistical Center of Iran. 2016.

31. Pan $Y$, Guan H, Zhou S, Wang $Y$, Li Q, Zhu T, et al. Initial $C T$ findings and temporal changes in patients with the novel coronavirus pneumonia (2019-nCoV): a study of 63 patients in Wuhan, China. Eur Radiol. 2020;30:1-4.

32. Chen Y-C. A tutorial on kernel density estimation and recent advances. Biostat Epidemiol. 2017;1(1):161-87. https://doi.org/10.1080/24709360.201 7.1396742.

33. Moons E, Brijs T, Wets G. Hot spot analysis: Improving a local indicator of spatial association for application in traffic safety. Springer; 2008:221-231. https://doi.org/10.1007/978-3-540-69839-5_17.

34. Shabanikiya H, Hashtarkhani S, Bergquist R, Bagheri N, VafaeiNejad R, AmiriGholanlou M, et al. Multiple-scale spatial analysis of paediatric, pedestrian road traffic injuries in a major city in north-eastern Iran 2015-2019. BMC Public Health. 2020;20(1):722. https://doi.org/10.1186/s12889-020-08911-2.

35. Ord JK, Getis A. Local spatial autocorrelation statistics: distributional issues and an application. Geogr Anal. 1995;27:286-306.

36. Anselin L, Syabri I, Kho Y. GeoDa: an introduction to spatial data analysis. In: Handbook of applied spatial analysis: Springer; 2010. p. 73-89.

37. Kiani B, Rahmati A, Bergquist R, Moghaddas E. Comparing spatio-temporal distribution of the most common human parasitic infections in Iran over two periods 2007 to 2012 and 2013 to 2018: A systematic quantitative literature review. Int J Health Plan Manag. 35(5):1023-40.

38. Richardson S, Hirsch JS, Narasimhan M, Crawford JM, McGinn T, Davidson $\mathrm{KW}$, et al. Presenting characteristics, comorbidities, and outcomes among 5700 patients hospitalized with COVID-19 in the new York City area. JAMA 2020;323(20):2052-9. https://doi.org/10.1001/jama.2020.6775.

39. Jin J-M, Bai P, He W, Wu F, Liu X-F, Han D-M, et al. Gender differences in patients with COVID-19: focus on severity and mortality. Front Public Health. 2020;8. https://doi.org/10.3389/fpubh.2020.00152.

40. NeJhaddadgar N, Ziapour A, Zakkipour G, Abbas J, Abolfathi M, Shabani M. Effectiveness of telephone-based screening and triage during COVID-19 outbreak in the promoted primary healthcare system: a case study in Ardabil province, Iran. J Public Health. 2020. https://doi.org/10.1007/s10389-020-01407-8.

41. Yoosefi Lebni J, Abbas J, Moradi F, Salahshoor MR, Chaboksavar F, Irandoost SF, et al. How the COVID-19 pandemic effected economic, social, political, and cultural factors: A lesson from Iran. Int J Soc Psychiatry. 2020;2: 0020764020939984.

42. Grasselli G, Zangrillo A, Zanella A, Antonelli M, Cabrini L, Castelli A, et al. Baseline characteristics and outcomes of 1591 patients infected with SARSCoV-2 admitted to ICUs of the Lombardy region, Italy. JAMA. 2020;323(16): 1574-81. https://doi.org/10.1001/jama.2020.5394.

43. Wang $R$, Pan M, Zhang X, Han M, Fan X, Zhao F, et al. Epidemiological and clinical features of 125 hospitalized patients with COVID-19 in Fuyang, Anhui, China. Int J Infect Dis. 2020;95:421-8. https://doi.org/10.1016/j.ijid.202 0.03.070.

44. Abbas J. The impact of coronavirus (SARS-CoV2) epidemic on individuals mental health: the protective measures of Pakistan in managing and sustaining transmissible disease. Psychiatr Danub. 2020;32(3-4):472-7. https://doi.org/10.24869/psyd.2020.472.

45. Emami A, Javanmardi F, Pirbonyeh N, Akbari A. Prevalence of underlying diseases in hospitalized patients with COVID-19: a systematic review and meta-analysis. Arch Acad Emerg Med. 2020;8 https://www.ncbi.nlm.nih.gov/ pmc/articles/PMC7096724/. Accessed 29 Sep 2020.

46. Passamonti F, Cattaneo C, Arcaini L, Bruna R, Cavo M, Merli F, et al. Clinical characteristics and risk factors associated with COVID-19 severity in patients with haematological malignancies in Italy: a retrospective, multicentre, cohort study. Lancet Haematol. 2020;7(10):e737-45. https://doi.org/10.1016/ S2352-3026(20)30251-9.
47. Javanian M, Bayani M, Shokri M, Sadeghi-Haddad-Zavareh M, Babazadeh A, Yeganeh B, et al. Clinical and laboratory findings from patients with COVID-19 pneumonia in Babol north of Iran: a retrospective cohort study. Roman J Internal Med. 2020;58(3):161-7. https://doi.org/10.2478/riim-2020-0013.

48. Ma Y, Hou L, Yang X, Huang Z, Yang X, Zhao N, et al. The association between frailty and severe disease among COVID-19 patients aged over 60 years in China: a prospective cohort study. BMC Med. 2020;18:1-8.

49. Samrah SM, Al-Mistarehi A-H W, Ibnian AM, Raffee LA, Momany SM, Al-Ali M, et al. COVID-19 outbreak in Jordan: epidemiological features, clinical characteristics, and laboratory findings. Ann Med Surg. 2020;57:103-8. https://doi.org/10.1016/j.amsu.2020.07.020.

50. Shafi AMA, Shaikh SA, Shirke MM, Iddawela S, Harky A. Cardiac manifestations in COVID-19 patients-A systematic review. J Card Surg. 2020;35(8):1988-2008. https://doi.org/10.1111/jocs.14808.

51. Momtazmanesh S, Shobeiri P, Hanaei S, Mahmoud-Elsayed H, Dalvi B, Malakan RE. Cardiovascular disease in COVID-19: a systematic review and meta-analysis of 10,898 patients and proposal of a triage risk stratification tool. Egypt Heart J. 2020;72(1):41. https://doi.org/10.1186/ s43044-020-00075-z.

52. Bakhshayeh S, Hoseini B, Bergquist R, Nabovati E, Gholoobi A, MohammadEbrahimi S, et al. Cost-utility analysis of home-based cardiac rehabilitation as compared to usual post-discharge care: systematic review and meta-analysis of randomized controlled trials. Exp Rev Cardiovasc Ther. 2020;3:1-6.

53. Maddison R, Rawstorn JC, Stewart RAH, Benatar J, Whittaker R, Rolleston A, et al. Effects and costs of real-time cardiac telerehabilitation: randomised controlled non-inferiority trial. Heart. 2019;105:122-9.

54. Barron E, Bakhai C, Kar P, Weaver A, Bradley D, Ismail H, Knighton P, Holman N, Khunti K, Sattar N, Wareham NJ, Young B, Valabhij J Associations of type 1 and type 2 diabetes with COVID-19-related mortality in England: a wholepopulation study. Lancet Diabet Endocrinol 2020;0. doi:https://doi.org/10.1 016/S2213-8587(20)30272-2, 8, 10, 813, 822.

55. Xie Y, Wang Z, Liao H, Marley G, Wu D, Tang W. Epidemiologic, clinical, and laboratory findings of the COVID-19 in the current pandemic: systematic review and meta-analysis. BMC Infect Dis. 2020;20(1):640. https://doi.org/1 0.1186/s12879-020-05371-2.

56. CDC. Coronavirus Disease 2019 (COVID-19) - Symptoms: Centers for Disease Control and Prevention; 2020. https://www.cdc.gov/coronavirus/2019-ncov/ symptoms-testing/symptoms.html. Accessed 4 Oct 2020

57. Lian J, Jin X, Hao S, Cai H, Zhang S, Zheng L, et al. Analysis of epidemiological and clinical features in older patients with coronavirus disease 2019 (COVID-19) outside Wuhan. Clin Infect Dis. 2020;71(15):740-7. https://doi.org/10.1093/cid/ciaa242.

58. Bhatraju PK, Ghassemieh BJ, Nichols M, Kim R, Jerome KR, Nalla AK, et al. Covid-19 in critically ill patients in the Seattle region - case series. N Engl J Med. 2020;382(21):2012-22. https://doi.org/10.1056/NEJMoa2004500.

59. Arentz M, Yim E, Klaff L, Lokhandwala S, Riedo FX, Chong M, et al. Characteristics and outcomes of 21 critically ill patients with COVID-19 in Washington state. JAMA. 2020;323(16):1612-4. https://doi.org/10.1001/ja ma.2020.4326.

60. Shuja KH, Shahidullah N, Aqeel M, Khan EA, Abbas J. Letter to highlight the effects of isolation on elderly during COVID-19 outbreak. Int J Geriatr Psychiatry. 2020;35(12):1477-8. https://doi.org/10.1002/gps.5423.

61. Abbas J. Crisis management, transnational healthcare challenges and opportunities: the intersection of COVID-19 pandemic and global mental health. Res Global. 2021;3:100037. https://doi.org/10.1016/j. resglo.2021.100037.

62. Abbas J, Wang D, Su Z, Ziapour A. The role of social Media in the Advent of COVID-19 pandemic: crisis management, mental health challenges and implications. Risk Manag Healthc Policy. 2021;14:1917-32. https://doi.org/1 0.2147/RMHP.S284313.

63. Abdollahi E, Haworth-Brockman M, Keynan Y, Langley JM, Moghadas SM. Simulating the effect of school closure during COVID-19 outbreaks in Ontario, Canada. BMC Med. 2020;18(1):230. https://doi.org/10.1186/s12916-020-01705-8.

64. Maqsood A, Abbas J, Rehman G, Mubeen R. The paradigm shift for educational system continuance in the advent of COVID-19 pandemic: mental health challenges and reflections. Curr Res Behav Sci. 2021;2:100011. https://doi.org/10.1016/j.crbeha.2020.100011.

65. Fathi-Kazerooni S, Rojas-Cessa R, Dong Z, Umpaichitra V. Correlation of subway turnstile entries and COVID-19 incidence and deaths in new York City. Infect Dis Model. 2021;6:183-94. https://doi.org/10.1016/j.idm.2 020.11.006. 
66. Hamidi S, Hamidi I. Subway ridership, crowding, or population density: determinants of COVID-19 infection rates in new York City. Am J Prev Med. 2021;60(5):614-20. https://doi.org/10.1016/j.amepre.2020.11.016.

67. Azizi MR, Atlasi R, Ziapour A, Abbas J, Naemi R. Innovative human resource management strategies during the COVID-19 pandemic: A systematic narrative review approach. Heliyon. 2021;7:e07233.

68. Abbas J, Mubeen R, lorember PT, Raza S, Mamirkulova G. Exploring the impact of COVID-19 on tourism: transformational potential and implications for a sustainable recovery of the travel and leisure industry. Curr Res Behav Sci. 2021;2:100033. https://doi.org/10.1016/j.crbeha.2021.100033.

69. Pourghasemi HR. Spatial modelling, risk mapping, change detection, and outbreak trend analysis of coronavirus (COVID-19) in Iran (days between 19 February to 14 June 2020). Int J Infect Dis. 2020;98:90-108.

70. Chavehpour Y, Rashidian A, Woldemichael A, Takian A. Inequality in geographical distribution of hospitals and hospital beds in densely populated metropolitan cities of Iran. BMC Health Serv Res. 2019;19(1):614. https://doi.org/10.1186/s12913-019-4443-0.

71. COVID-19 National Incident Room Surveillance Team. COVID-19, Australia: Epidemiology Report 16 (Reporting week to 23:59 AEST 17 May 2020). Commun Dis Intell. 2018;2020:44

72. Bazargan M. A case study on accessibility of medical and healthcare facilities in Mashhad using GIS. SAUES J. 2018;1:39-48.

73. Samimi T, MohammadEbrahimi S, Tara F, Mostafavi SM, Miandehi EE, Tara M. Improving information adequacy of clinical morning reports: development of a structured model in the obstetrics and gynecology department. Health Educ Health Promot. 2021; [In press]

\section{Publisher's Note}

Springer Nature remains neutral with regard to jurisdictional claims in published maps and institutional affiliations.

Ready to submit your research? Choose BMC and benefit from:

- fast, convenient online submission

- thorough peer review by experienced researchers in your field

- rapid publication on acceptance

- support for research data, including large and complex data types

- gold Open Access which fosters wider collaboration and increased citations

- maximum visibility for your research: over $100 \mathrm{M}$ website views per year

At $\mathrm{BMC}$, research is always in progress.

Learn more biomedcentral.com/submissions 